www.nature.com/ja

\title{
Three new depsipeptides, JBIR-113, JBIR-114 and JBIR-115, isolated from a marine sponge-derived Penicillium sp. fS36
}

\author{
Teppei Kawahara ${ }^{1}$, Motoki Takagi ${ }^{1}$ and Kazuo Shin-ya ${ }^{2}$
}

The Journal of Antibiotics (2012) 65, 147-150; doi:10.1038/ja.2011.126; published online 21 December 2011

Keywords: depsipeptides; marine sponge; Penicillium

Fungi found in marine habitats constitute a rarely exploited but promising resource for the discovery of novel bioactive substances, ${ }^{1}$ such as diketopiperazine alkaloids, ${ }^{2}$ trichodermatides ${ }^{3}$ and carbonarones. ${ }^{4}$ We recently discovered novel compounds, namely, aspochracin derivative JBIR-15, ${ }^{5}$ glycosyl benzenediols JBIR-37 and $-38,{ }^{6}$ sorbicillinoids JBIR-59 ${ }^{7}$ and $-124,{ }^{8}$ xanthoquinodin JBIR-97, -98 and $-99,{ }^{9}$ and JBIR-74 and $-75,{ }^{10}$ which were obtained from marine spongederived fungi. Therefore, we attempted to isolate fungi from abyssal sea marine sponges to obtain novel substances of fungal origin. In this study, we isolated three new depsipeptides termed JBIR-113 (1), JBIR114 (2) and JBIR-115 (3) from a culture of Penicillium sp. fS36 that was obtained from a marine sponge (Figure 1a). This paper describes the fermentation, isolation and structural elucidations of $\mathbf{1 - 3}$.

Penicillium sp. fS36 was isolated from an unidentified marine sponge collected at a depth of $195 \mathrm{~m}$ from a position (i.e., $28^{\circ} 53^{\prime}$ $35.8^{\prime \prime} \mathrm{N}, 129^{\circ} 29^{\prime} 57.0^{\prime \prime}$ E) near Takarajima Island, Kagoshima Prefecture, Japan. The sponge was ground using a mortar and pestle. These pieces were suspended in sterile seawater and the suspension spread on manila clam extract agar. ${ }^{11}$ The isolated strain was maintained on potato dextrose agar medium (BD Biosciences, San Jose, CA, USA). The sequence analysis of ribosomal DNA and internal transcribed spacer region of the producing fungus showed high sequence similarities with Penicillium namyslowskii (AB028190, $100 \%)$. The strain was cultivated in $50 \mathrm{ml}$ test tubes containing $15 \mathrm{ml}$ of potato dextrose medium $\left(24 \mathrm{gl}^{-1}\right.$ potato dextrose; BD Biosciences). The test tubes were shaken using a reciprocal shaker (320 r.p.m.) at $27^{\circ} \mathrm{C}$ for 2 days. Aliquots $(5 \mathrm{ml})$ of the culture were transferred to $500 \mathrm{ml}$ Erlenmeyer flasks containing brown rice $(15 \mathrm{~g}$, Hitomebore, Miyagi, Japan), Bacto-yeast extract (30 mg, BD Bios- ciences), sodium tartarate $(15 \mathrm{mg})$, dipotassium hydrogenphosphate $(15 \mathrm{mg})$ and water $(45 \mathrm{ml})$ and were incubated in a static culture at $27^{\circ} \mathrm{C}$ for 14 days.

The culture (10 flasks) was extracted with $80 \%$ aqueous $\mathrm{Me}_{2} \mathrm{CO}$ (11) and the extract was filtered. After concentration in vacuo, water $(600 \mathrm{ml})$ was added to the residual aqueous solution followed by extraction with EtOAc $(700 \mathrm{ml} \times 3)$. The organic layer was dried over anhydrous $\mathrm{Na}_{2} \mathrm{SO}_{4}$ and evaporated. The residual portion $(2.5 \mathrm{~g})$ was subjected to normal-phase medium-pressure liquid chromatography (Purif-Pack SI-30, Shoko Scientific Co., Yokohama, Japan) and developed with a gradient system of $n$-hexane-EtOAc (0-25\% EtOAc) followed by a stepwise solvent system comprising $\mathrm{CHCl}_{3}-\mathrm{MeOH}(0,2$, $5,10,20,30$ and $100 \% \mathrm{MeOH})$. The fractions including 1-3 were collected by LC-MS monitoring. The $5 \% \mathrm{MeOH}$ eluate $(230 \mathrm{mg})$ was applied on a Sephadex LH-20 column (GE Healthcare BioSciences AB, Uppsala, Sweden) and developed with $\mathrm{CHCl}_{3}-\mathrm{MeOH}(1: 1)$ to obtain the crude material $(38.1 \mathrm{mg})$. Compounds 1 (9.9 mg), $2(1.7 \mathrm{mg})$ and $3(1.7 \mathrm{mg})$ were obtained by preparative reversed-phase HPLC on a CAPCELL PAK C18 MGII column $(5.0 \mu \mathrm{m}$, internal diameter $20 \times 150 \mathrm{~mm}$; Shiseido, Tokyo, Japan) with $55 \%$ aqueous $\mathrm{MeOH}$ containing $0.1 \%$ formic acid (flow rate: $10 \mathrm{ml} \mathrm{min}^{-1}$; retention times: $25.4 \mathrm{~min}$ for 1 ; $17.4 \mathrm{~min}$ for 2 ; $12.8 \mathrm{~min}$ for 3 ).

Compound $\mathbf{1}$ is a colorless amorphous solid with the following properties: $[\alpha]_{\mathrm{D}}^{22}-87.7(\mathrm{MeOH} ; c 0.15)$; UV $\lambda_{\max }(\varepsilon)$ in $\mathrm{MeOH}: 223$ $(17000)$ and $270(900) \mathrm{nm}$; and IR absorption $\left(v_{\max }\right) 1654$ and $1751 \mathrm{~cm}^{-1}$. The molecular formula of 1 was determined to be $\mathrm{C}_{31} \mathrm{H}_{41} \mathrm{~N}_{5} \mathrm{O}_{7}$ using high resolution-ESI-MS $\left(m / z 596.3098[\mathrm{M}+\mathrm{H}]^{+}\right.$; calculated for $\mathrm{C}_{31} \mathrm{H}_{42} \mathrm{~N}_{5} \mathrm{O}_{7} \mathrm{~m} / z$ 596.3084). Its peptidic nature was evident from the abundance of resonances corresponding to amide

${ }^{1}$ Biomedicinal Information Research Center (BIRC), Japan Biological Informatics Consortium (JBIC), Tokyo, Japan and ${ }^{2}$ Biomedicinal Information Research Center (BIRC), National Institute of Advanced Industrial Science, and Technology (AIST), Tokyo, Japan

Correspondence: Dr M Takagi, Biomedicinal Information Research Center (BIRC), Japan Biological Informatics Consortium (JBIC), 2-4-7 Aomi, Koto-ku, Tokyo 135-0064, Japan. E-mail: motoki-takagi@aist.go.jp

or Dr K Shin-ya, Biomedicinal Information Research Centre (BIRC), National Institute of Advanced Industrial Science and Technology (AIST), 2-4-7 Aomi, Koto-ku, Tokyo 135-0064, Japan.

E-mail: k-shinya@aist.go.jp

Received 1 November 2011; revised 29 November 2011; accepted 30 November 2011; published online 21 December 2011 

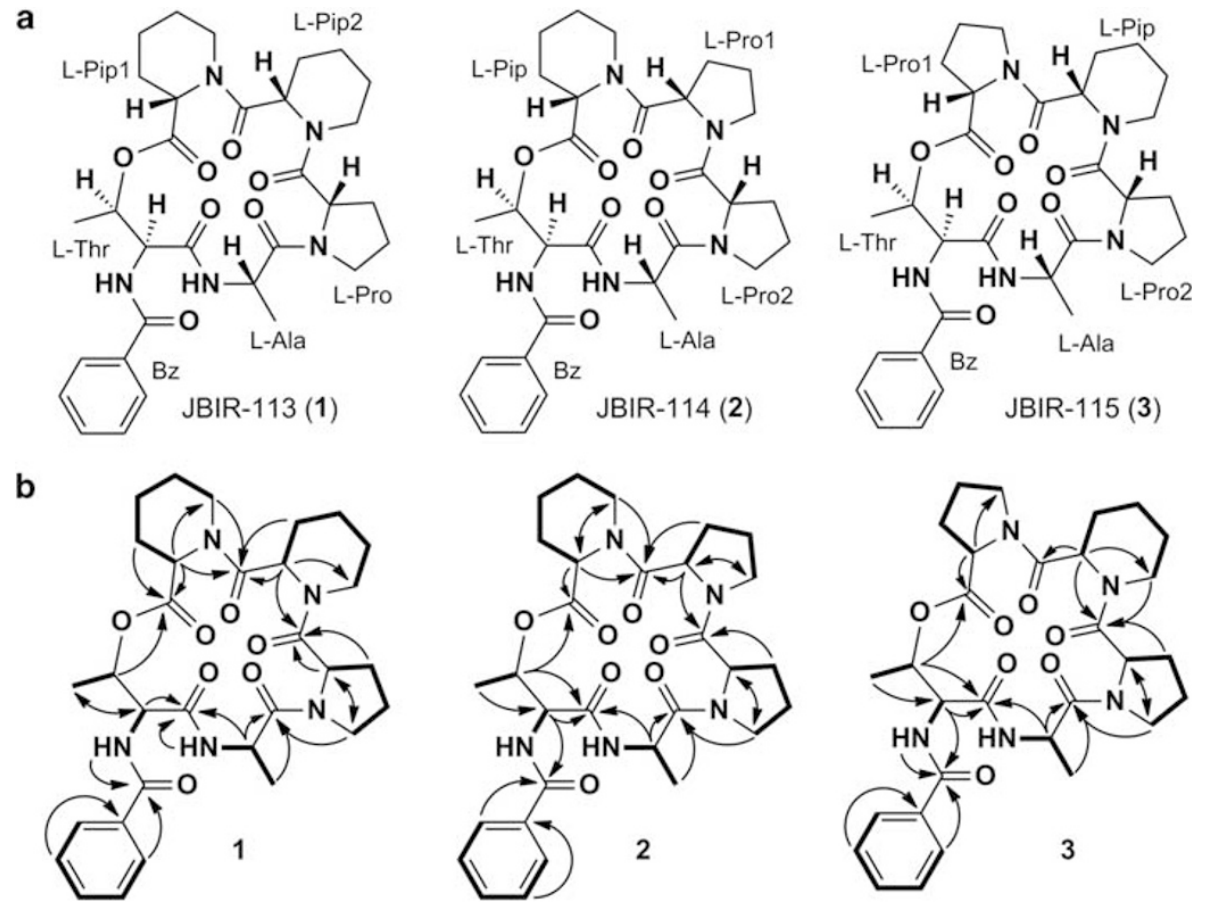

Figure 1 (a) Structures of JBIR-113 (1), JBIR-114 (2), and JBIR-115 (3). (b) Key correlations of double quantum-filtered (DQF)-COSY (bold lines) and HMBC (arrows, proton to carbon) of 1 .

$\mathrm{NH}$ protons $\left(\delta_{\mathrm{H}} 7.14-7.52\right)$ and the resonances corresponding to the carbonyl carbons $\left(\delta_{\mathrm{C}} 167.8-174.3\right)$ in the ${ }^{1} \mathrm{H}$ and ${ }^{13} \mathrm{C}$ NMR spectra of 1, respectively (Table 1). The direct connectivity between protons and carbons was established via a heteronuclear single quantum coherence spectrum; the ${ }^{13} \mathrm{C}$ and ${ }^{1} \mathrm{H}$ NMR spectroscopic data of $\mathbf{1}$ is shown in Table 1 . The ${ }^{1} \mathrm{H}$ sequences and ${ }^{1} \mathrm{H}-{ }^{13} \mathrm{C}$ long-range couplings from the $\alpha$-methine protons to the corresponding amide carbonyl carbons, which were elucidated using double quantum-filtered (DQF)-COSY and constant time heteronuclear multiple bond correlation $(\mathrm{CT}-\mathrm{HMBC})^{12}$ spectra, respectively, proved the presence of a Pro, an Ala, a Thr and two pipecolic acids (Pip) residues, as shown in Figure 1. The residual benzoyl $(\mathrm{Bz})$ group in $\mathbf{1}$ was revealed by consecutive COSY correlations from aromatic proton $\mathrm{Bz}-3 / 7-\mathrm{H}\left(\delta_{\mathrm{H}} 7.85\right)$ to $\mathrm{Bz}-5-$ $\mathrm{H}\left(\delta_{\mathrm{H}} 7.52\right)$ through $\mathrm{Bz}-4 / 6-\mathrm{H}\left(\delta_{\mathrm{H}} 7.45\right)$ and by the HMBC correlations from Bz-4/6-H to aromatic carbon Bz-C-2 $\left(\delta_{\mathrm{C}} 134.2\right)$ and from $\mathrm{Bz}-3 / 7-\mathrm{H}$ to amide carbonyl carbon Bz-C-1 $(\delta$ 167.8). The amino-acid sequence and substituted position of the $\mathrm{Bz}$ moiety in $\mathbf{1}$ were determined via the ${ }^{1} \mathrm{H}_{-}{ }^{13} \mathrm{C}$ long-range correlations from an $\alpha$-methine proton Pip1-2-H $\left(\delta_{\mathrm{H}} 4.43\right)$ and a $\varepsilon$-methylene proton Pip1-6a-H $\left(\delta_{\mathrm{H}}\right.$ $4.19)$ to a carbonyl carbon Pip2-C-1 $\left(\delta_{\mathrm{C}} 174.3\right)$, from an $\alpha$-methine proton Pip2-2-H $\left(\delta_{\mathrm{H}} 4.68\right)$ to a carbonyl carbon of Pro $\left(\delta_{\mathrm{C}} 170.9\right)$, from $\delta$-methylene protons Pro-5a-H $\left(\delta_{\mathrm{H}} 3.66\right)$ and Pro-5b-H $\left(\delta_{\mathrm{H}}\right.$ $3.59)$ to a carbonyl carbon Ala-C-1 $\left(\delta_{\mathrm{C}} 172.6\right)$, from an $\alpha$-methine proton Ala-2-H $\left(\delta_{\mathrm{H}} 4.25\right)$ and an amide proton Ala- $\mathrm{NH}\left(\delta_{\mathrm{H}} 7.33\right)$ to a carbonyl carbon Thr-C-1 $\left(\delta_{\mathrm{C}} 168.0\right)$, and from an amide amine proton Thr-NH $\left(\delta_{\mathrm{H}} 7.14\right)$ to the carbonyl carbon Bz-C-1. Additionally, an HMBC correlation from an oxymethine proton Thr-3-H $\left(\delta_{\mathrm{H}} 5.28\right)$ to a carbonyl carbon Pip1-C-1 $\left(\delta_{\mathrm{C}} 169.3\right)$ established that Thr and Pip-1 are connected through an ester bond. Thus, the planar structure of 1 shown in Figure la was established.

The absolute configurations of the amino-acid residues in $\mathbf{1}$ were determined using Marfey's method. ${ }^{13}$ Accordingly, 1 (0.4 mg) was hydrolyzed in $6 \mathrm{~N} \mathrm{HCl}(200 \mu \mathrm{l})$ at $110^{\circ} \mathrm{C}$ for $12 \mathrm{~h}$. After drying the reaction solution under an $\mathrm{N}_{2}$ gas flow, $0.5 \mathrm{M} \mathrm{NaHCO} 3(40 \mu \mathrm{l})$ and $10 \mathrm{~mm} \quad \mathrm{~N}$-(5-fluoro-2,4-dinitrophenyl)-L-alaninamide (FDAA) in $\mathrm{Me}_{2} \mathrm{CO}(60 \mu \mathrm{l})$ were added. The mixture was then reacted at $60^{\circ} \mathrm{C}$ for $20 \mathrm{~min}$. The resultant products were analyzed using a UPLC-TOFMS system (Waters, ACQUITY) as follows: a Waters BEH ODS column (internal diameter $2.1 \times 50 \mathrm{~mm}$ ) was developed with an aqueous MeCN-containing $0.1 \%$ formic acid linear gradient system

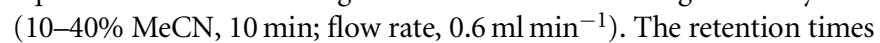
of the FDAA derivatives were determined by monitoring the UV absorption at $340 \mathrm{~nm}$ in the positive and negative mode of HR-ESIMS. By comparing the retention times of standard amino-acid FDAA derivatives and FDAA derivatives of $\mathbf{1}$, the amino-acid residues in $\mathbf{1}$ were established to be in the L form (i.e., standard amino-acid FDAA derivatives: L-Pip (6.82 $\mathrm{min})$, D-Pip (6.33 $\mathrm{min})$, L-Pro (4.49 $\mathrm{min})$, D-Pro (4.96 min), L-Ala (3.97 $\mathrm{min})$, D-Ala (5.08 $\mathrm{min})$, L-Thr (3.08 $\mathrm{min})$, and D-Thr (3.62 min); target FDAA derivatives: Pips (6.82 min), Pro $(4.49 \mathrm{~min})$, Ala $(3.97 \mathrm{~min})$ and $\mathrm{Thr}(3.08 \mathrm{~min}))$. Therefore, the structure of 1 including the absolute configuration was determined, as shown in Figure 1a.

Compound 2 features the following properties: $[\alpha]_{\mathrm{D}}^{22}-26.4(\mathrm{MeOH}$; c 0.08); UV $\lambda_{\max }(\varepsilon)$ in MeOH: 210 (26000) nm; HR-ESI-MS: $m / z$ 582.2928 $[\mathrm{M}+\mathrm{H}]^{+}$, calculated for $\mathrm{C}_{30} \mathrm{H}_{40} \mathrm{~N}_{5} \mathrm{O}_{7} \mathrm{~m} / z$ 582.2928; and IR absorption $\left(v_{\max }\right) 1656$ and $1751 \mathrm{~cm}^{-1}$. The properties of 3 are as follows: $[\alpha]_{\mathrm{D}}^{22}-37.8(\mathrm{MeOH} ; c$ 0.08); HR-ESI-MS: $\mathrm{m} / \mathrm{z} 582.2905$ $[\mathrm{M}+\mathrm{H}]^{+}$, calculated for $\mathrm{C}_{30} \mathrm{H}_{40} \mathrm{~N}_{5} \mathrm{O}_{7} \mathrm{~m} / z$ 582.2928; UV $\lambda_{\max }(\varepsilon)$ in MeOH: $210(16000)$ and $271(2200) \mathrm{nm}$; and IR absorption $\left(v_{\max }\right)$ 1652 and $1751 \mathrm{~cm}^{-1}$. NMR spectroscopic analysis of 2 and 3 revealed that both compounds comprise a Thr, Ala, Pip and two Pro residues (Table 1).

The sequence of amino-acid residues in $\mathbf{2}$ was established via the following $\mathrm{HMBC}$ correlations (Figure 1b): from an $\alpha$-methine 
Table $1{ }^{13} \mathrm{C}$ and ${ }^{1} \mathrm{H}$ NMR spectroscopic data for JBIR-113 (1), JBIR-114 (2) and JBIR-115 (3).

\begin{tabular}{|c|c|c|c|c|c|c|c|c|c|c|c|}
\hline \multicolumn{4}{|r|}{$1^{\mathrm{a}}$} & \multicolumn{4}{|r|}{$2^{a}$} & \multicolumn{4}{|r|}{$3^{b}$} \\
\hline Unit & Position & $\delta_{C}$ & $\delta_{H}$, mult $(\mathrm{J}$ in $\mathrm{Hz})$ & Unit & Position & $\delta_{C}$ & $\delta_{H}$, mult $(\mathrm{J}$ in $\mathrm{Hz})$ & Unit & Position & $\delta_{C}$ & $\delta_{H}$, mult $(\mathrm{J}$ in $\mathrm{Hz})$ \\
\hline \multirow[t]{9}{*}{ Pip1 } & 1 & 169.3 & & Pip & 1 & 169.1 & & Pro1 & 1 & 170.4 & \\
\hline & 2 & 53.9 & $4.43, d(6.0)$ & & 2 & 54.2 & $4.64, \mathrm{ovl}^{\mathrm{c}}$ & & 2 & 58.4 & $4.28, \mathrm{dd}(1.2,7.2)$ \\
\hline & $3 a$ & 27.2 & $1.89, \mathrm{ovl}^{\mathrm{C}}$ & & $3 a$ & 27.5 & 1.93, ovlc & & $3 a$ & 31.4 & $1.63, \mathrm{ovl}^{\mathrm{C}}$ \\
\hline & $3 b$ & & $1.77, \mathrm{ovl}^{\mathrm{C}}$ & & $3 b$ & & $1.78, \mathrm{ovl}^{\mathrm{C}}$ & & $3 b$ & & $1.47, \mathrm{ovl}^{\mathrm{C}}$ \\
\hline & 4 & 18.7 & $1.63, \mathrm{ovl}^{\mathrm{C}}$ & & 4 & 18.9 & $1.63, \mathrm{ovl}^{\mathrm{C}}$ & & $4 a$ & 22.2 & $2.00, \mathrm{~m}$ \\
\hline & $5 a$ & 24.16 & $1.81, \mathrm{ovl}^{\mathrm{C}}$ & & $5 a$ & 24.2 & $1.81, \mathrm{ovl}^{\mathrm{c}}$ & & $4 b$ & & $1.18, \mathrm{~m}$ \\
\hline & $5 b$ & & $1.37, \mathrm{~m}$ & & $5 b$ & & $1.37, \mathrm{~m}$ & & $5 a$ & 46.4 & 3.82 , ddd $(3.2,9.1,12.0)$ \\
\hline & $6 a$ & 39.1 & $4.19, \mathrm{dd}(3.5,13.0)$ & & $6 a$ & 39.4 & $4.28, \mathrm{ovl}^{\mathrm{C}}$ & & $5 b$ & & 3.28, ddd $(7.9,7.9,12.0)$ \\
\hline & $6 b$ & & 3.29, ddd $(3.5,13.0,13.0)$ & & $6 b$ & & 3.37, ddd $(3.0,13.5,13.5)$ & & & & \\
\hline \multirow[t]{9}{*}{ Pip2 } & 1 & 174.3 & & Pro1 & 1 & 173.3 & & Pip & 1 & 171.8 & \\
\hline & 2 & 50.9 & $4.68, \mathrm{dd}(3.5,7.0)$ & & 2 & 56.5 & 4.65, ovlc & & 2 & 51.5 & 5.03, dd $(2.4,7.1)$ \\
\hline & $3 a$ & 26.1 & $1.94, \mathrm{ovl}^{\mathrm{C}}$ & & $3 a$ & 28.9 & $2.22, \mathrm{~m}$ & & $3 a$ & 26.3 & $2.08, \mathrm{ovl}^{\mathrm{C}}$ \\
\hline & $3 b$ & & $1.81, \mathrm{ovl}^{\mathrm{C}}$ & & $3 b$ & & $1.91, \mathrm{ovl}^{\mathrm{c}}$ & & $3 b$ & & $1.68, \mathrm{ovl}^{\mathrm{c}}$ \\
\hline & $4 a$ & 18.8 & $1.69, \mathrm{ovl}^{\mathrm{c}}$ & & $4 a$ & 25.8 & $2.23, \mathrm{~m}$ & & 4 & 19.3 & $1.50, \mathrm{ovl}^{\mathrm{C}}$ \\
\hline & $5 a$ & 24.22 & $1.82, \mathrm{ovl}^{\mathrm{C}}$ & & $4 b$ & & $2.07, \mathrm{~m}$ & & $5 a$ & 24.9 & $1.41, \mathrm{ovl}^{\mathrm{C}}$ \\
\hline & $5 b$ & & $1.68, \mathrm{ovl}^{\mathrm{c}}$ & & $5 a$ & 46.8 & $3.68, \mathrm{ovl}^{\mathrm{c}}$ & & $5 b$ & & $1.36, \mathrm{ovl}^{\mathrm{C}}$ \\
\hline & $6 a$ & 43.2 & $3.70, \mathrm{ovl}^{\mathrm{c}}$ & & $5 b$ & & $3.63, \mathrm{ovl}^{\mathrm{c}}$ & & $6 a$ & 43.0 & $3.80, \mathrm{dd}(4.1,12.6)$ \\
\hline & & & $3.68, \mathrm{ovl}^{\mathrm{c}}$ & & & & & & $6 b$ & & 3.13, br d (12.6) \\
\hline \multirow[t]{8}{*}{ Pro } & 1 & 170.9 & & Pro2 & 1 & 167.9 & & Pro2 & 1 & 171.0 & \\
\hline & 2 & 59.1 & 4.57, dd $(6.5,6.5)$ & & 2 & 59.2 & 4.46, dd $(5.5,8.0)$ & & 2 & 58.8 & 4.00, dd $(5.6,8.6)$ \\
\hline & $3 a$ & 30.0 & 2.37, ddd $(6.5,13.5,13.5)$ & & $3 a$ & 29.9 & $2.38, \mathrm{~m}$ & & $3 a$ & 30.0 & $1.63, \mathrm{ovl}^{\mathrm{C}}$ \\
\hline & $3 b$ & & 2.06, ddd $(6.5,13.5,13.5)$ & & $3 b$ & & $2.12, \mathrm{ovl}^{\mathrm{c}}$ & & $3 b$ & & $1.55, \mathrm{~m}$ \\
\hline & $4 a$ & 23.1 & $1.85, \mathrm{ovl}^{\mathrm{C}}$ & & $4 a$ & 23.1 & $1.90, \mathrm{ovl}^{\mathrm{c}}$ & & $4 a$ & 22.9 & $1.28, \mathrm{dd}(6.8,12.9)$ \\
\hline & $4 b$ & & $1.79, \mathrm{ovl}^{\mathrm{c}}$ & & $4 b$ & & $1.80, \mathrm{ovl}^{\mathrm{c}}$ & & $4 b$ & & $1.10, \mathrm{dd}(7.1,12.9)$ \\
\hline & $5 a$ & 47.4 & $3.66, \mathrm{ovl}^{\mathrm{c}}$ & & $5 a$ & 47.0 & $3.69, \mathrm{ovl}^{\mathrm{C}}$ & & $5 a$ & 47.7 & 3.58 , ddd $(7.1,7.1,12.4)$ \\
\hline & $5 b$ & & 3.59, ddd $(5.4,6.8,12.0)$ & & $5 b$ & & $3.50, \mathrm{dd}(6.5,12.0)$ & & $5 b$ & & 3.51, ddd $(6.8,6.8,12.4)$ \\
\hline \multirow[t]{4}{*}{ Ala } & 1 & 172.6 & & Ala & 1 & 172.2 & & Ala & 1 & 172.5 & \\
\hline & 2 & 47.3 & $4.25, \mathrm{dq}(6.5,8.5)$ & & 2 & 47.4 & $4.24, \mathrm{q}(6.5)$ & & 2 & 47.5 & $4.50, \mathrm{dq}(1.8,6.7)$ \\
\hline & 3 & 19.8 & $1.25, \mathrm{~d}(6.5)$ & & 3 & 19.8 & $1.26, \mathrm{~d}(6.5)$ & & 3 & 20.0 & $1.36, \mathrm{~d}(6.7)$ \\
\hline & $\mathrm{NH}$ & & $7.33, \mathrm{~d}(8.5)$ & & $\mathrm{NH}$ & & 6.86, br s & & $\mathrm{NH}$ & & 8.16, br s \\
\hline \multirow[t]{5}{*}{ Thr } & 1 & 168.0 & & Thr & 1 & $167.6^{d}$ & & Thr & 1 & 168.5 & \\
\hline & 2 & 55.6 & $4.94, \mathrm{~d},(9.0)$ & & 2 & 55.7 & $4.86, d(8.5)$ & & 2 & 55.8 & 5.37, br d (8.6) \\
\hline & 3 & 73.4 & $5.28, \mathrm{q}(6.4)$ & & 3 & 73.2 & $5.25, \mathrm{q}(6.5)$ & & 3 & 74.8 & $5.74, \mathrm{q}(6.5)$ \\
\hline & 4 & 17.2 & $1.33, \mathrm{~d}(6.4)$ & & 4 & 17.1 & $1.32, \mathrm{~d}(6.5)$ & & 4 & 17.9 & $1.51, \mathrm{~d}(6.5)$ \\
\hline & $\mathrm{NH}$ & & $7.14, \mathrm{~d}(9.0)$ & & $\mathrm{NH}$ & & $7.07, d(8.5)$ & & $\mathrm{NH}$ & & $7.52, \mathrm{~d}(8.6)$ \\
\hline \multirow[t]{5}{*}{$\mathrm{Bz}$} & 1 & 167.8 & & $\mathrm{Bz}$ & 1 & $167.6^{d}$ & & $\mathrm{Bz}$ & 1 & 166.9 & \\
\hline & 2 & 134.2 & & & 2 & 134.2 & & & 2 & 134.8 & \\
\hline & $3 / 7$ & 127.3 & $7.85, \mathrm{~d}(7.3)$ & & $3 / 7$ & 127.3 & $7.85, \mathrm{~d}(7.5)$ & & $3 / 7$ & 127.4 & $7.90, \mathrm{~d}(7.5)$ \\
\hline & $4 / 6$ & 128.5 & 7.45, dd (7.3) & & $4 / 6$ & 128.6 & 7.46, dd $(7.5,7.5)$ & & $4 / 6$ & 128.2 & 6.92, dd $(7.5,7.5)$ \\
\hline & 5 & 131.7 & 7.52, dd $(7.3,7.3)$ & & 5 & 131.8 & 7.52, dd $(7.5,7.5)$ & & 5 & 131.1 & 6.98, dd $(7.5,7.5)$ \\
\hline
\end{tabular}

a Measured on a $500 \mathrm{NB} \mathrm{CL} \mathrm{NMR} \mathrm{instrument} \mathrm{(Varian,} \mathrm{Palo} \mathrm{Alto,} \mathrm{CA,} \mathrm{USA)} \mathrm{at} 500 \mathrm{MHz}$ for ${ }^{1} \mathrm{H}$ and $125 \mathrm{MHz}$ for ${ }^{13} \mathrm{C}$ with the residual solvent peak as the internal standards (in CDCl 3 , 7.25 p.p.m. for ${ }^{1} \mathrm{H}$ and 77.0 p.p.m. for ${ }^{13} \mathrm{C}$ ).

bMeasured on a $600 \mathrm{NB} \mathrm{CL} \mathrm{NMR} \mathrm{instrument} \mathrm{(Varian)} \mathrm{at} 600 \mathrm{MHz}$ for ${ }^{1} \mathrm{H}$ and $150 \mathrm{MHz}$ for ${ }^{13} \mathrm{C}$ with the residual solvent peak as the internal standard (in $\mathrm{C}_{6} \mathrm{D}_{6}, 7.15 \mathrm{p} . \mathrm{p} . \mathrm{m}$. for ${ }^{1} \mathrm{H}$ and 128.0 p.p.m. for ${ }^{13} \mathrm{C}$ ).

cOverlapped with other signals.

dInterchangeable.

proton Pip-2-H $\left(\delta_{\mathrm{H}} 4.64\right)$ to a carbonyl carbon of Pro1 $\left(\delta_{\mathrm{C}} 173.3\right)$, from an $\alpha$-methine proton Prol-2-H $\left(\delta_{\mathrm{H}} 4.65\right)$ to a carbonyl carbon of Pro2 $\left(\delta_{\mathrm{C}} 167.9\right)$, from a $\delta$-methylene proton Pro2$5 \mathrm{a}-\mathrm{H}\left(\delta_{\mathrm{H}} 3.69\right)$ to a carbonyl carbon of Ala $\left(\delta_{\mathrm{C}} 172.2\right)$, from an $\alpha$-methine proton Ala-2-H $\left(\delta_{\mathrm{H}} 4.24\right)$ to carbonyl carbon of Thr $\left(\delta_{\mathrm{C}}\right.$ 167.6), from Thr-3-H $\left(\delta_{\mathrm{H}} 5.25\right)$ to carbonyl carbon of Pip1
$\left(\delta_{\mathrm{C}} 169.1\right)$, and from Thr-2-H $\left(\delta_{\mathrm{H}} 4.86\right)$ to Bz-C-1 $\left(\delta_{\mathrm{C}} 167.6\right)$ (Figure 1b).

The ${ }^{1} \mathrm{H}$ and ${ }^{13} \mathrm{C}$ NMR spectra of 3 in $\mathrm{CDCl}_{3}$ were very similar to those of 2 . As the signals observed for the ${ }^{1} \mathrm{H}$ NMR spectrum of 3 in $\mathrm{CDCl}_{3}$ significantly overlapped, we determined the NMR spectra of 3 in $\mathrm{C}_{6} \mathrm{D}_{6} \cdot{ }^{1} \mathrm{H}-{ }^{13} \mathrm{C}$ long-range correlations from an $\alpha$-methine proton 
Pip-2-H $\left(\delta_{\mathrm{H}} 5.03\right)$ and $\varepsilon$-methylene proton Pip-6b-H $\left(\delta_{\mathrm{H}} 3.13\right)$ to carbonyl carbon Pro2-C-1 $\left(\delta_{\mathrm{C}} 171.0\right)$, from $\delta$-methylene proton Pro2-5a-H $\left(\delta_{\mathrm{H}} 3.58\right)$ to carbonyl carbon of Ala $\left(\delta_{\mathrm{C}} 172.5\right)$, from an $\alpha$-methine proton Ala-2-H $\left(\delta_{\mathrm{H}} 4.50\right)$ to a carbonyl carbon Thr-C-1 $\left(\delta_{\mathrm{C}}\right.$ 168.5), from an oxymethine proton Thr-3-H $\left(\delta_{\mathrm{H}} 5.74\right)$ to a carbonyl carbon Pro1-C-1 $\left(\delta_{\mathrm{C}} 170.4\right)$, from an amide amine proton of Thr $\left(\delta_{\mathrm{H}} 7.52\right)$ and an $\alpha$-methine proton Thr-2-H $\left(\delta_{\mathrm{H}} 5.37\right)$ to a carbonyl carbon Bz-C-1 $\left(\delta_{\mathrm{C}} 166.9\right)$ were observed (Figure 1b). According to the index of hydrogen deficiency of 14 that was calculated from the molecular formula of 3 , the nitrogen atom in Pro1 should form a peptide bond with carbonyl carbon Pip-1-C $\left(\delta_{\mathrm{C}}\right.$ 171.8). Thus, the planar structure of 3 was elucidated.

The absolute configurations of the amino acids in $\mathbf{2}$ and $\mathbf{3}$ were determined to be L-Pip, L-Pro $(\times 2)$, L-Ala and L-Thr using the same methods as for 1 (Figure 1a).

We evaluated the cytotoxic and antimicrobial activities of 1-3, but 1-3 did not show cytotoxicity to human cervical carcinoma HeLa cells lines $\left(\mathrm{IC}_{50}>100 \mu \mathrm{M}\right)$ or antimicrobial activity against Micrococcus luteus, or Escherichia coli.

The elucidated structures of $\mathbf{1 - 3}$ are structurally related to petrosifungins that were isolated from a marine sponge-derived fungus. ${ }^{14}$ Although other peptides containing pipecolic acid have been reported including neamphamide $\mathrm{A}^{15}$ from a marine sponge and microsporins $\mathrm{A}$ and $\mathrm{B}^{16}$ from a marine sponge-derived fungus, these peptides are very rare in natural products and are all of marine origin. The results of this study suggest that fungi isolated from marine sponges in abyssal sea possess the desirable ability to produce unique compounds.

\section{ACKNOWLEDGEMENTS}

This work was supported by a grant from the New Energy and Industrial Technology Department Organization (NEDO) of Japan. The sponge was collected during the NT-09-17 cruise of Natsushima, Japan Agency for MarineEarth Science and Technology (JAMSTEC).
1 Saleem, M. et al. Marine natural products of fungal origin. Nat. Prod. Rep. 24, 11421152 (2007).

2 Zhang, M. et al. Cytotoxic alkaloids and antibiotic nordammarane triterpenoids from the marine-derived fungus Aspergillus sydowi. J. Nat. Prod. 71, 985-989 (2008).

3 Sun, Y. et al. Trichodermatides A-D, novel polyketides from the marine-derived fungus Trichoderma reesei. Org. Lett. 10, 393-396 (2008).

4 Zhang, Y. et al. Carbonarones $A$ and $B$, new bioactive $\gamma$-pyrone and $\alpha$-pyridone derivatives from the marine-derived fungus Aspergillus carbonarius. J. Antibiot. 60, 153-157 (2007).

5 Motohashi, K., Inaba, S., Takagi, M. \& Shin-ya, K. JBIR-15, a new aspochracin derivative, isolated from a sponge-derived fungus, Aspergillus sclerotiorum Huber Sp080903f04. Biosci. Biotechnol. Biochem. 73, 1898-1900 (2009).

6 Izumikawa, M. et al. JBIR-37 and -38, novel glycosyl benzenediols, isolated from the sponge-derived fungus, Acremonium sp. SpF080624G1f01. Biosci. Biotechnol. Biochem. 73, 2138-2140 (2009).

7 Ueda, J., Hashimoto, J., Inaba, S., Takagi, M. \& Shin-ya, K. JBIR-59, a new sorbicillinoid, from marine-derived fungus Penicillium citrinum Spl080624G1f01. J. Antibiot. 63, 203-205 (2010).

8 Kawahara, T., Takagi, M. \& Shin-ya, K. JBIR-124: a novel antioxidative agent from a marine sponge-derived fungus Penicillium citrinum Spl080624G1f01. J. Antibiot (2011)doi: 10.1038/ja.2011.98.

9 Ueda, J., Takagi, M. \& Shin-ya, K. New xanthoquinodin-like compounds, JBIR-97, -98 and -99 , obtained from marine sponge-derived fungus Tritirachium sp. SpB081112MEf2. J. Antibiot. 63, 615-618 (2010).

10 Takagi, M., Motohashi, K. \& Shin-ya, K. Isolation of 2 new metabolites, JBIR-74 and JBIR-75, from the sponge-derived Aspergillus sp. fS14. J. Antibiot. 63, 203-205 (2010).

11 Khan, S. T. et al. Streptomyces associated with a marine sponge Haliclona sp.; biosynthetic genes for secondary metabolites and products. Environ. Microbiol. 13, 729-731 (2011).

12 Furihata, K. \& Seto, H. Constant time HMBC (CT-HMBC), a new HMBC technique useful for improving separation of cross peaks. Tetrahedron Lett. 39, 7337-7340 (1998).

13 Marfey, P. Determination of d-amino acids. II. Use of a bifunctional reagent, 1,5difluoro-2,4-dinitrobenzene. Carlsberg Res. Commun. 49, 591-596 (1984).

14 Bringmann, G., Lang, G., Steffens, S. \& Schaumann, K. Petrosifungins A and B, nove cyclodepsipeptides from a sponge-derived strain of Penicillium brevicompactum. J. Nat. Prod. 67, 311-315 (2004).

15 Oku, N. et al. Neamphamide A, a new HIV-inhibitory depsipeptide from the Papua New Guinea marine sponge Neamphius huxleyi. J. Nat. Prod. 67, 1407-1411 (2004).

16 Gu, W., Cueto, M., Jensen, P. R., Fenical, W. \& Silverman, R. B. Microsporins A and B: new histone deacetylase inhibitors from the marine-derived fungus Microsporum cf. gypseum and the solid-phase synthesis of microsporin A. Tetrahedron 63, 6535-6541 (2007). 